\title{
Inter- and Intramolecular Dispersion Interactions
}

\author{
MARCEL SWART, ${ }^{\mathbf{1 , 2}}$ MIQUEL SOLÀ, ${ }^{\mathbf{1}}$ F. MATTHIAS BICKELHAUPT ${ }^{\mathbf{3}}$ \\ ${ }^{1}$ Institut de Química Computacional and Departament de Química, Universitat de Girona, \\ Campus Montilivi, 17071 Girona, Spain \\ ${ }^{2}$ Institució Catalana de Recerca i Estudis Avançats (ICREA), Pg. Lluís Companys 23, \\ 08010 Barcelona, Spain \\ ${ }^{3}$ Department of Theoretical Chemistry and Amsterdam Center for Multiscale Modeling, \\ Scheikundig Laboratorium der Vrije Universiteit, De Boelelaan 1083, 1081 HV Amsterdam, \\ The Netherlands
}

Received 2 July 2010; Revised 7 September 2010; Accepted 8 September 2010

DOI 10.1002/jcc.21693

Published online 4 November 2010 in Wiley Online Library (wileyonlinelibrary.com).

\begin{abstract}
We have investigated the performance of a variety of density functional methods for weak intra- and intermolecular dispersion interactions. Grimme's empirical dispersion correction method is shown to give a good description for these interactions and helps to improve the description of water-hexamer isomers, noble-gas dimers, hydrocarbon $\mathrm{C}_{12} \mathrm{H}_{12}$ isomers, branching energy of linear versus branched octane, dissociation of the covalently bound anthracene dimer, and stacking within the adenine dimer. However, the dispersion correction does not correct all shortcomings of the different density functionals, which leads to sizeable differences compared to $a b$ initio $\operatorname{CCSD}(\mathrm{T})$ and experimental reference data. The only exception is shown to be our recently presented SSB-D functional that works well for all systems studied here.
\end{abstract}

(C) 2010 Wiley Periodicals, Inc. J Comput Chem 32: 1117-1127, 2011

Key words: density functional theory; weak interactions; coupled cluster methods; water hexamers; hydrocarbon isomers

\section{Introduction}

The correct description of weak interactions (hydrogen-bonding, ${ }^{1-4} \pi-\pi$ stacking $^{5}$ ) is a challenge ${ }^{6}$ for theoretical chemistry methods. Although highly accurate coupled cluster methods are available, ${ }^{7-9}$ these are for everyday-use limited to small systems of up to 20-30 atoms. Moreover, the coupled cluster methods are for these systems only viable within single-point energy calculations, unless a large amount of computing resources is available. This was for instance the case in recent studies on the relative energies of water-hexamer isomers, ${ }^{10,11}$ where coupled cluster energies were obtained using MP2 geometries. On the other hand, density functional methods are much less computationally demanding, and much larger systems can be treated. However, the density functionals show in general a dramatic underestimation of these weak interactions. ${ }^{1,5}$ It had been argued ${ }^{12}$ that these underestimations could be easily understood by looking at the exchange enhancement factor at large values of $s$ (where $s$ is the usual reduced density gradient), but we have recently shown that the situation is not that simple. That is, by using a switching function, ${ }^{13}$ we showed that the $\pi-\pi$ stacking and hydrogen-bonding energy are almost completely determined by the region with $s<5$ a.u.; this was already found indirectly by Wesolowski et al. ${ }^{14}$ by comparing PW86 with PW91. Moreover, by applying and releasing the PBEx constraints ${ }^{15}$ on PBE, OPBE, and OLYP, we saw ${ }^{16}$ that there seems to be no correlation between the limiting values (at $s=0$ and $s=\infty$ ) of the enhancement factor and the weak interactions.

One of the more interesting manifestations of these challenging problems was a number of recent studies on the relative energies of different isomers of water-hexamer configurations. ${ }^{10,11}$ Benchmark data obtained at the coupled cluster $\operatorname{CCSD}(\mathrm{T})$ level with large basis sets ${ }^{10}$ (CCSD(T)/aug'-cc-pVTZ// MP2/aug-cc-pVTZ) and extrapolations ${ }^{11}$ to the complete basis

Additional Supporting Information may be found in the online version of this article.

Correspondence to: M. Swart; e-mail: marcel.swart@icrea.cat. Contract/grant sponsor: Ministerio de Ciencia e Innovación (MICINN); contract/grant numbers: CTQ2008-03077/BQU and CTQ2008-06532/BQU

Contract/grant sponsor: DIUE of the Generalitat de Catalunya; contract/grant numbers: 2009SGR637 and 2009SGR528

Contract/grant sponsor: The Netherlands Organization for Scientific Research (NWO-CW and NWO-NCF) and the National Research School Combination-Catalysis (NRSC-C) 
set (CBS) limit have been reported, which were used for comparing the performance of several standard density functional methods. None of the density functionals included in these studies was able to correctly predict the relative energy ordering for this series of hexamers. ${ }^{10}$ This failure of standard density functional methods was also shown by Grimme and coworkers to hold for two other systems (dimerization of anthracene, ${ }^{17}$ branching energy of octane ${ }^{18}$ ), where density functional methods were unable to give the correct sign of the reaction energy.

We have recently reported a new density functional (SSBD) ${ }^{19}$ that combines ${ }^{13}$ the best of the nonempirical PBE functional $^{15}$ with the best of the empirical OPBE functional. ${ }^{15,20-22}$ Interestingly, it works excellently for the systems put forward by Grimme as difficult cases for density functional methods, ${ }^{17,18}$ where not only the sign for the interaction energy was predicted correctly but also the absolute value. ${ }^{19}$ That is, our predicted values of $+10.6 \mathrm{kcal} \mathrm{mol}{ }^{-1}$ for the dissociation energy of the anthracene-dimer and $+2.1 \mathrm{kcal} \mathrm{mol}^{-1}$ for the branching energy of octane are within $1 \mathrm{kcal} \mathrm{mol}^{-1}$ from the best ab initio and experimental results $\left(9 \pm 3 \mathrm{kcal} \mathrm{mol}^{-1}\right.$ and $1.9 \pm 0.5 \mathrm{kcal} \mathrm{mol}^{-1}$ for the anthracene and octane systems, respectively). Similarly, a small deviation of $0.5 \mathrm{kcal} \mathrm{mol}^{-1}$ was found for the $\mathrm{S} 22 \mathrm{set}^{23}$ by Hobza and coworkers, which is a set that contains reference energies at the $\operatorname{CCSD}(\mathrm{T})$ level for weakly interacting systems. This good behavior of our SSB-D functional is in part due to the inclusion of Grimme's dispersion correction, ${ }^{24,25}$ but also because of the good performance of the nonempirical PBE functional for hydrogen-bonding interactions. ${ }^{16}$ Note that here we still use the "D2" dispersion correction, and not yet the "D3" correction that has recently become available. $^{26}$ This good behavior of SSB-D was not only shown for weak interactions but also for spin-state splittings of iron complexes, ${ }^{19}$ accuracy of geometries for both main-element compounds and transition-metal complexes, ${ }^{19}$ reaction barriers, ${ }^{19,27}$ magnetizabilities, ${ }^{28}$ energy profiles of $\mathrm{E} 2$ vs. $\mathrm{S}_{\mathrm{N}} 2$ reactions, ${ }^{27} \mathrm{Na}^{+} \cdots \mathrm{H}_{2} \mathrm{O}$ and $\mathrm{Cl}^{-} \cdots \mathrm{H}_{2} \mathrm{O}$ interactions, ${ }^{29}$ the polymerization mechanism in $\alpha$-diimine iron catalysts, ${ }^{30}$ and NMR nuclear shieldings. ${ }^{31}$ Note that the SSB-D functional is only a minor correction to $\mathrm{PBE}$, with parameters that are within $10 \%$ of the PBE parameters (see Table 1). Given in eq. (1) is the exchange enhancement factor for both PBE and SSB-D, with the full SSB-D energy expression given in the Supporting Information.

$$
F(s)=A+\frac{B s^{2}}{1+C s^{2}}-\frac{D(1-u) s^{2}}{1+E s^{4}}
$$

For the SSB-D functional, we had taken the Grimme approach, ${ }^{24,25}$ where the only parameter in the dispersion correction that was allowed to change is the $s_{6}$ parameter [see eq. (2)], whereas the $\alpha$ and $r_{0}$ parameters were left at their original values of 20 and 1.1, respectively (the $R_{\text {ref, } i}$ are atom-specific radii obtained by Grimme from ROHF/TZV calculations $\left.^{24,25}\right)$. Note that for SSB-D, this $s_{6}$ value $(0.847455$ for SSB-D) was optimized simultaneously with the other parameters and not adapted afterward, as is usually the case for other density functionals.
Table 1. Parameters of PBE, SSB-D, ${ }^{19}$ and revSSB-D Functionals ${ }^{\mathrm{a}, \mathrm{b}}$.

\begin{tabular}{lccc}
\hline & PBE & SSB-D & revSSB-D \\
\hline$A$ & 1 & 1.079966 & 1.082138 \\
$B$ & 0.219515 & 0.197465 & 0.177998 \\
$C$ & $0.273029^{\mathrm{c}}$ & $0.272729^{\mathrm{c}}$ & $0.246582^{\mathrm{c}}$ \\
$D$ & - & $0.197465^{\mathrm{d}}$ & $0.177998^{\mathrm{d}}$ \\
$E$ & - & 5.873645 & 6.284673 \\
$u$ & - & -0.749940 & -0.618168 \\
$F$ & - & 0.949488 & 1.0 \\
$s_{6}$ & $-\left(0.75^{\mathrm{e}}\right)$ & 0.847455 & 1.0 \\
$r_{0}$ & $-\left(1.1^{\mathrm{e}}\right)$ & 1.1 & 1.3 \\
\hline
\end{tabular}

${ }^{a}$ The complete energy expressions are given in the Supporting Information.

${ }^{\mathrm{b}}$ All parameters in atomic units, except $r_{0}$ (which is a dimensionless factor).

${ }^{c}$ constrained to fulfill $A+B / C=1.804$.

${ }^{\mathrm{d}}$ Constrained to $D=B$.

${ }^{\mathrm{e}}$ For PBE-D.

$$
\begin{gathered}
E_{\mathrm{disp}}=-s_{6} \sum_{i=1}^{N-1} \sum_{j=i+1}^{N} \frac{C_{6, i j}}{R_{i j}^{6}} f_{d m p}\left(R_{i j}\right) \\
f_{\mathrm{dmp}}\left(R_{i j}\right)=\left[1+e^{\alpha-\alpha\left(R_{i j} / R_{\mathrm{ref}}\right)}\right]^{-1} \\
R_{\mathrm{ref}}=r_{0} \cdot\left(R_{\mathrm{ref}, i}+R_{\mathrm{ref}, j}\right)
\end{gathered}
$$

However, in several studies, ${ }^{32,33}$ it was argued that adjusting $s_{6}$ would ruin the long-range attractive force, i.e., it would either make the attractive forces too weak $\left(s_{6}<1\right)$ or too strong $\left(s_{6}>1\right)$. Therefore, it was suggested to set the $s_{6}$ parameter to 1 and adjust the $r_{0}$ parameter instead for the different functionals; the PBEsol-D functional is a recent example of this latter line of thought (which gave an $r_{0}$ value of 1.42). Here, we follow the same procedure and report the revised SSB-D functional (revSSB-D), where $s_{6}$ was set to 1 , and $r_{0}$ allowed to adjust simultaneously with the other parameters (see Table 1; a full description of the performance of revSSB-D for standard benchmark systems is given in the Supporting Information; see also ref. 19 for the performance of SSB-D). Similar to our procedure for SSB-D, we used several constraints on the parameters, e.g., to satisfy the Lieb-Oxford bound and to reduce the number of parameters (six for SSB-D and revSSB-D).

Here, we report the application of our SSB-D and revSSB-D functionals to a number of systems where weak interactions are important. In particular, we have studied the six isomers of water-hexamer systems, dimers of noble gases, 12 isomers of $\mathrm{C}_{12} \mathrm{H}_{12}$ hydrocarbons, Grimme's difficult systems (branching energy of octane, dimerization of anthracene), and the stacking of adenine dimers. For all of these systems, accurate reference data at the $\operatorname{CCSD}(\mathrm{T})$ level are available, either from the literature or calculated here.

\section{Computational Details}

Most of the density functional calculations have been performed with a locally modified version of NWChem $5.1 .1^{34}$ (to include the SSB-D, revSSB-D, PBEsol, and PBEsol-D functionals), 


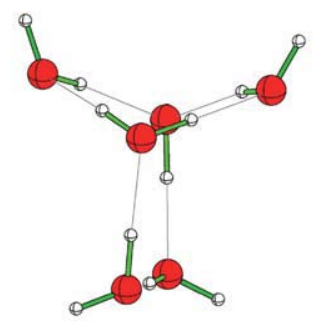

bag

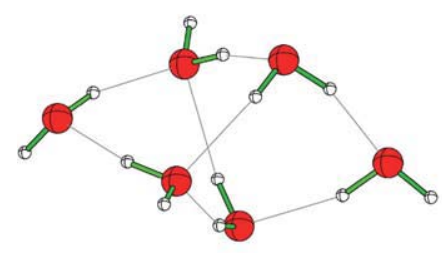

cage

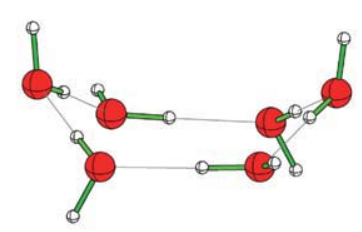

boat

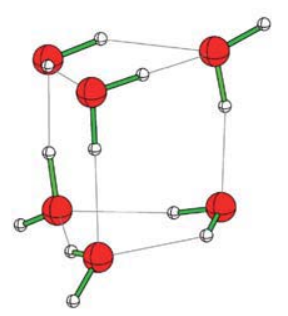

prism

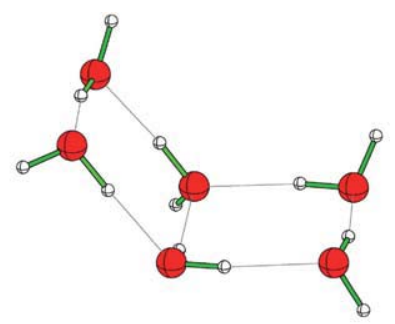

book

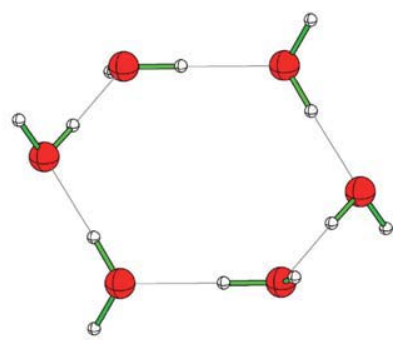

ring

Scheme 1. The six water-hexamer isomers considered.

whereas Gaussian09 $9^{35}$ was used for the B2PLYP and B2PLYP-D functionals. For the noble-gas dimers with their very shallow energy profiles, use was made of QUILD ${ }^{36}$ because of its superior geometry optimization routines. ${ }^{37}$ The MP2/aug'-cc-pVTZ geometry of the $\mathrm{C}_{12} \mathrm{H}_{12}$ isomers were obtained with NWChem, while the subsequent single-point coupled cluster calculations have been performed with the CFOUR program (version 1.2). ${ }^{38,39}$

A variety of Dunning's correlation consistent basis sets have been used, ranging from cc-pVDZ and cc-pVTZ for the CCSD(T) energy calculations (and cc-pVQZ for the RHF CBS extrapolation) in the case of the $\mathrm{C}_{12} \mathrm{H}_{12}$ isomers, to aug-ccpVQZ for the noble-gas dimers, to aug'-cc-pVTZ for the other systems such as the water-hexamer isomers. The latter basis set consists of aug-cc-pVTZ on the non-hydrogen atoms combined with cc-pVTZ on $\mathrm{H}$.

For most systems, we did not take basis set superposition error (BSSE) corrections into account, for two reasons. First, because the reference energies of those systems (mostly at $\operatorname{CCSD}(\mathrm{T})$ level) were also not corrected for BSSE. Second, the basis set used here mostly ( $\mathrm{aug}^{\prime}$-cc-pVTZ) is for the density functionals very close to the basis set limit. The only exception has been the adenine dimer for which the reference CBS(T) energies had been obtained with BSSE corrections, and therefore, we have done the same here.

\section{Results and Discussion}

The relative energies for six different isomers of water-hexamer systems (see Scheme 1) were studied by Truhlar and coworkers using the aug' ${ }^{\prime}$-cc-pVTZ basis, ${ }^{10}$ and subsequently extrapolated to the CBS limit by Bates and Tschumper. ${ }^{11}$ It is worth noting that for the book and boat conformations, there is at least another possible less stable isomer not considered here. The extrapolation to the CBS limit resulted in energy changes of less than $0.05 \mathrm{kcal}$ $\mathrm{mol}^{-1}$; therefore, for these water hexamers, the aug'-cc-pVTZ is sufficiently large. All six isomers are found within a range of 2.9 $\mathrm{kcal} \mathrm{mol}^{-1}$, with the difference between the most stable isomer (prism, see Scheme 1) and the second-most stable (cage) being only $0.2 \mathrm{kcal} \mathrm{mol}^{-1}$ at $\operatorname{CCSD}(\mathrm{T}) / \mathrm{aug}^{\prime}$-cc-pVTZ. ${ }^{10}$

Relatively narrow ranges were also observed for several density functional methods, but with even smaller values of e.g. $1.8 \mathrm{kcal}$ $\mathrm{mol}^{-1}$ for PBE/MG3S (see Table 2). On the other hand, other density functionals showed a much larger range such as M06-2X/MG3S with $5.5 \mathrm{kcal} \mathrm{mol}^{-1}$. More importantly, almost all density functionals were unable to recognize the prism isomer as the most stable one, with the exception of the Minnesota functionals mPWB1K, PWB6K, M05-2X, and M06-2X. ${ }^{10}$ However, the former two did not predict the correct order of the isomers (see Table 2), whereas the latter two functionals severely overestimated the energy differences with a total energy range of $4.7 \mathrm{kcal} \mathrm{mol}^{-1}(\mathrm{M} 05-2 \mathrm{X})$ and $5.5 \mathrm{kcal}$ $\mathrm{mol}^{-1}$ (M06-2X). These latter ranges are almost twice as large as the $\operatorname{CCSD}(\mathrm{T})$ range. Truhlar and coworkers showed that the density functionals gave geometries that are similar to the MP2 geometry; therefore, we have taken the same approach here and computed only single-point energies using the MP2 geometries, which can then be compared directly to the CCSD(T) energy.

The deviation of the density functional data from the $\operatorname{CCSD}(\mathrm{T})$ energies reported in ref. 10 is partly due to the basis sets used by Truhlar and coworkers for the density functional calculations (6$\left.311+\mathrm{G}(2 \mathrm{~d}, 2 \mathrm{p}), \mathrm{aug}^{\prime}-\mathrm{cc}-\mathrm{pVTZ}, \mathrm{MG} 3 \mathrm{~S}\right)$, which are different from the one used (aug'-cc-pVTZ) for the MP2 and $\operatorname{CCSD}(\mathrm{T})$ calculations. ${ }^{10}$ For instance, the BLYP data differed by up to $0.6 \mathrm{kcal}$ $\mathrm{mol}^{-1}$ between the $6-311+\mathrm{G}(2 \mathrm{~d}, 2 \mathrm{p})$ and the MG3S basis sets, whereas the PBE data even differed up to $1 \mathrm{kcal} \mathrm{mol}^{-1}$ (but this is probably partly due to a typographical error in ref. 10, vide infra). Given the small range observed for the relative energies (of up to $3 \mathrm{kcal} \mathrm{mol}^{-1}$ ), the use of the other basis sets is not satisfactory. 
Table 2. Relative Energies $\left(\mathrm{kcal} \mathrm{mol}^{-1}\right)$ of Water-Hexamer Isomers Using the aug'-cc-pVTZ Basis Set ${ }^{\mathrm{a}, \mathrm{b}}$.

\begin{tabular}{|c|c|c|c|c|c|c|c|}
\hline Method & prism & cage & book & bag & ring & boat & $M U E^{\mathrm{c}}$ \\
\hline $\operatorname{CCSD}(\mathrm{T})$ & 0 & 0.21 & 0.71 & 1.57 & 1.83 & 2.84 & - \\
\hline MP2 & 0 & 0.01 & 0.31 & & 1.25 & 2.25 & 0.27 \\
\hline $\mathrm{PBE}^{\mathrm{d}}$ & 0 & 0.05 & -0.47 & 0.49 & 0.13 & 1.29 & 0.84 \\
\hline $\mathrm{mPWB} 1 \mathrm{~K}^{\mathrm{d}}$ & 0 & 0.31 & 0.60 & 1.70 & 0.82 & 1.95 & 0.59 \\
\hline M05-2X $\mathrm{X}^{\mathrm{d}}$ & 0 & 0.84 & 2.16 & 2.99 & 3.53 & 4.68 & 0.83 \\
\hline M06-2X $\mathrm{X}^{\mathrm{d}}$ & 0 & 0.94 & 2.84 & 3.64 & 4.41 & 5.50 & 1.27 \\
\hline PWB6K & 0 & 0.44 & 0.94 & 1.96 & 1.45 & .56 & 0.37 \\
\hline BLYP & 0 & & & & & & 1.94 \\
\hline BLY & ( & & & & & & 0.45 \\
\hline B3L & 0 & & -1 . & & 66 & & 1.74 \\
\hline B3LY & 0 & & & & & & 0.16 \\
\hline PBE & 0 & 0 & & 0 & 0 & 49 & 1.09 \\
\hline 3E-D & 0 & & 1 & 1 & .58 & 3.73 & 0.65 \\
\hline $\mathrm{Pl}$ & 0 & & 1 . & 0.62 & 2.08 & 1.63 & 1.10 \\
\hline PBEsol- & 0 & & 1.97 & 1.04 & 3.55 & 3.02 & 1.06 \\
\hline OPBE & 0 & -0.21 & -4.24 & -3.78 & -7.05 & -6.04 & 4.68 \\
\hline B3PW91 & 0 & 0.07 & -0.55 & 0.24 & -0.41 & 0.32 & 1.27 \\
\hline B3PW91-D & 0 & 0.76 & 2.39 & 2.62 & 4.52 & 70 & 1.43 \\
\hline B2PLYP & 0 & 0.09 & -0.45 & 0.49 & -0.21 & 0.90 & 1.05 \\
\hline B2PLYP-D & 0 & 0.40 & 0.90 & 1.58 & 2.06 & 3.16 & 0.15 \\
\hline B97-D & 0 & 0.25 & -0.10 & 0.23 & 0.45 & 1.50 & 0.78 \\
\hline & 0 & 0.71 & 1.49 & 2.00 & 3.20 & 4.11 & 0.64 \\
\hline revSSB-D & 0 & 0.31 & 0.74 & 1.28 & 2.12 & 3.21 & 0.28 \\
\hline
\end{tabular}

${ }^{\text {a }}$ Single-point energy calculations on the MP2/aug'-cc-pVTZ geometries (see text).

${ }^{\mathrm{b}}$ Indicated in bold are those energies where either the wrong isomer has the lowest energy, or where the ordering of the different isomers is wrong.

${ }^{c}$ Mean unsigned error between all pairs of isomers, according to Truhlar et al. definition. ${ }^{10}$

${ }^{\mathrm{d}}$ With MG3S basis set, from ref. 10.

Here, we have used the aug'-cc-pVTZ basis set that was also used for MP2 and $\operatorname{CCSD}(\mathrm{T})$ to allow for a better comparison. Results obtained with this basis showed differences in relative energies for PBE and BLYP between 0.5 and $0.8 \mathrm{kcal} \mathrm{mol}^{-1}$ compared to either the $6-311+G(2 d, 2 p)$ or the MG3S basis sets. Likewise, for PBE, we have also tested the aug-cc-pVTZ basis set, which gives differences of less than $0.05 \mathrm{kcal} \mathrm{mol}^{-1}$ from the results with the aug'-cc-pVTZ basis. The PBE/aug-cc-pVTZ data reported in ref. 10 are very different from our PBE energies with either the aug'cc-pVTZ or the aug-cc-pVTZ basis set and are instead more similar to the B3LYP/MG3S data. Therefore, it is most likely that there has been a typographical error for the "PBE/aug-cc-pVTZ" data in ref. 10 .

Our results with the aug'-cc-pVTZ basis set (see Table 2) show that one of the most important contributions to the interaction energies of the water hexamers is obtained by Grimme's dispersion correction. That is, none of the density functionals without it (including the double hybrid B2PLYP), is able to correctly predict the relative energies for these systems. For instance, the nonempirical PBE functional that usually performs well for hydrogen-bonded systems, predicts almost the same energy for the prism, book, and bag isomers. At the $\operatorname{CCSD}(\mathrm{T})$ level, these latter two isomers are found at, respectively, 0.7 and $1.6 \mathrm{kcal} \mathrm{mol}^{-1}$ above the most stable prism isomer. The inclusion of dispersion corrections improves the performance of the different functionals (see Table 2), but it does not correct all shortcomings. For instance, the PBE-D and PBEsol-D functionals still give the wrong ordering for the isomers, BLYP-D increases the separation between the prism and cage isomers to $0.8 \mathrm{kcal} \mathrm{mol}^{-1}$ (from 0.4 for BLYP) and predicts a too small separation between the cage and bag isomers, B3PW91-D doubles the energy range to $5.7 \mathrm{kcal} \mathrm{mol}^{-1}$, and B97-D gives both the wrong most-stable isomer and the wrong ordering.

The SSB-D results for the water hexamers are good, with the correct ordering of the different isomers but the relative energies are somewhat too large (with a mean unsigned error (MUE, between all pairs of isomers ${ }^{10}$ ) value of $0.6 \mathrm{kcal} \mathrm{mol}^{-1}$ ). This is further improved upon by BLYP-D, B3LYP-D, B2PLYP-D and the revised SSB-D functional (revSSB-D) that give excellent results with both the correct ordering of the isomers and small deviations from the $\operatorname{CCSD}(\mathrm{T})$ reference data (MUE value $0.2-0.3 \mathrm{kcal} \mathrm{mol}^{-1}$, see Table 2). Interestingly, the best option for the choice of setting the $s_{6}$ parameter (either to one or different from one) remains unsolved. Both SSB-D $\left(s_{6}=0.847455\right)$ and revSSB-D $\left(s_{6}=1.0\right)$ predict the correct ordering, with a smaller MUE value observed for the latter. This might indicate that the best option should be setting $s_{6}$ to one. However, the other two well-working functionals, B3LYP-D and B2PLYP-D, follow both the Grimme approach with $s_{6}$ values of, respectively, 1.05 and 0.55 . Moreover, the PBEsol-D functional with a $s_{6}$ value of 1.0 is unable the correctly predict the ordering of the isomers. Therefore, there is no clear preference for using either the Grimme $\left(s_{6} \neq 1.0\right)$ or the long-range $\left(s_{6}=1.0\right)$ approach.

\section{Noble Gas Dimers}

One of the prototypical systems for studying weakly interacting systems is posed by the noble gas dimers, which are bound only by dispersion interactions. The resulting stabilization is, therefore, very weak and ranges in the order from $-0.02 \mathrm{kcal} \mathrm{mol}^{-1}$ for $\mathrm{He}_{2}$ to $-0.38 \mathrm{kcal} \mathrm{mol}^{-1}$ for $\mathrm{Kr}_{2}$ (see Table 3 ). For most of the density functionals without the dispersion correction, these systems are difficult to describe, i.e., they give unbound dimers with the noble gas atoms separated at large distances. This is for instance the case for BLYP, B3LYP, B3PW91 and surprisingly enough also the much heralded ${ }^{43}$ B2PLYP. In contrast PBE and PBEsol work well and also OPBE gives bound dimers, albeit at elevated distances and with a severe underestimation of the binding energies. Inclusion of the dispersion correction improves in most cases (see Table 3), and leads in all cases to bound dimers with small deviations from the $\operatorname{CCSD}(\mathrm{T})$ reference data (see Table 3). Typical deviations from the $\operatorname{CCSD}(\mathrm{T})$ data are $0.1-0.3 \AA$ for the mean absolute deviation (MAD) value in the distances, and $0.1-0.3 \mathrm{kcal}$ $\mathrm{mol}^{-1}$ for the binding energies. Finally, SSB-D and revSSB-D perform quite well, especially the latter. Therefore, the bonding interactions in these very weakly bound systems are well described by the inclusion of the dispersion corrections.

\section{Twelve $\mathrm{C}_{12} \mathrm{H}_{12}$ Isomers}

There have been a number of studies ${ }^{32,44-49}$ on isomers of the $\mathrm{C}_{12} \mathrm{H}_{12}$ hydrocarbon, which was all triggered by a report of the preparation and reactivity of $\mathrm{D}_{3 \mathrm{~d}^{-}}$-octahedrane. ${ }^{44,45}$ This latter 
Table 3. Optimized Noble-Gas Dimer Distances $(\AA)$ and Bonding Energies $\left(\mathrm{kcal} \mathrm{mol}^{-1}\right)^{\mathrm{a}}$ Obtained with $\operatorname{CCSD}(\mathrm{T})^{\mathrm{b}}$ and Density Functionals ${ }^{\mathrm{c}}$.

\begin{tabular}{llllll}
\hline \multicolumn{1}{c}{ Method } & \multicolumn{1}{c}{$\mathrm{He}_{2}$} & \multicolumn{1}{c}{$\mathrm{Ne}_{2}$} & \multicolumn{1}{c}{$\mathrm{Ar}_{2}$} & \multicolumn{1}{c}{$\mathrm{Kr}_{2}$} & $\mathrm{MAD}$ \\
\hline CCSD(T) & & & & \\
BLYP & $2.98 /-0.02$ & $3.10 /-0.08$ & $3.78 /-0.27$ & $4.06 /-0.38$ & \\
BLYP-D & $6.25 / 0.00$ & $6.09^{\mathrm{d}} / 0.17$ & $6.11^{\mathrm{d}} / 0.35$ & $6.55^{\mathrm{d}} / 0.35$ & $2.77 / 0.41$ \\
B3LYP & $5.49 / 0.00$ & $2.93 /-0.07$ & $3.88 /-0.09$ & $4.07 /-0.28$ & $0.69 / 0.08$ \\
B3LYP-D & $5.87 / 0.00$ & $5.94^{\mathrm{d}} / 0.08$ & $6.05^{\mathrm{d}} / 0.19$ & $6.17^{\mathrm{d}} / 0.20$ & $2.52 / 0.30$ \\
PBE & $2.88 / 0.01$ & $2.85 /-0.16$ & $3.78 /-0.18$ & $4.01 /-0.38$ & $0.10 / 0.05$ \\
PBE-D & $2.75 /-0.08$ & $3.09 /-0.12$ & $4.00 /-0.14$ & $4.35 /-0.16$ & $0.19 / 0.11$ \\
PBEsol & $2.66 /-0.11$ & $2.90 /-0.28$ & $3.75 /-0.39$ & $3.99 /-0.59$ & $0.16 / 0.15$ \\
PBEsol-D & $2.86 /-0.05$ & $3.14 /-0.08$ & $3.98 /-0.11$ & $4.23 /-0.14$ & $0.13 / 0.11$ \\
OPBE & $2.81 /-0.08$ & $3.27 /-0.15$ & $4.18 /-0.22$ & $4.54 /-0.31$ & $0.30 / 0.06$ \\
M05-2X & $3.36 /-0.02$ & $3.83 /-0.03$ & $5.05 /-0.02$ & $5.43 /-0.03$ & $0.94 / 0.16$ \\
B3PW91 & $2.75 /-0.08$ & $2.89 /-0.15$ & $3.80 /-0.22$ & $4.11 /-0.31$ & $0.13 / 0.06$ \\
B3PW91-D & $5.74 / 0.00$ & $5.99^{\mathrm{d}} / 0.21$ & $7.55 / 0.00$ & $6.15^{\mathrm{d}} / 0.19$ & $2.88 / 0.29$ \\
B2PLYP & $4.99 / 0.00$ & $3.10 /-0.04$ & $3.72 /-0.19$ & $3.88 /-0.55$ & $0.56 / 0.08$ \\
B2PLYP-D & $3.93 \% / 0.03$ & $4.21^{\mathrm{d}} / 0.01$ & $5.72 \mathrm{~d} / 0.01$ & $5.69 \mathrm{~d} / 0.02$ & $1.41 / 0.20$ \\
B97-D & $3.04 / 0.01$ & $2.95 /-0.07$ & $4.04 /-0.05$ & $4.30 /-0.11$ & $0.18 / 0.13$ \\
SSB-D & $3.01 /-0.05$ & $3.28 /-0.15$ & $4.05 /-0.26$ & $4.15 /-0.49$ & $0.14 / 0.06$ \\
revSSB-D & $2.55 /-0.16$ & $2.82 /-0.39$ & $3.68 /-0.54$ & $3.95 /-0.76$ & $0.23 / 0.27$ \\
& $2.61 /-0.15$ & $3.01 /-0.29$ & $3.90 /-0.42$ & $4.25 /-0.57$ & $0.19 / 0.17$
\end{tabular}

\footnotetext{
${ }^{a}$ Values given as distance/energy.

${ }^{b}$ Basis sets used: aug-cc-pV6Z (He $),{ }^{40}$ aug-cc-pV5Z+bond-functions $\left(\mathrm{Ne}_{2}\right){ }^{41}$ aug-cc-pV6Z $\left(\mathrm{Ar}_{2}\right),{ }^{42}$ aug-cc-pV5Z+ spdfg $\left(\mathrm{Kr}_{2}\right){ }^{42}$

${ }^{c}$ With aug-cc-pVQZ basis.

${ }^{\mathrm{d}}$ Failed to converge in 50 geometry iterations; unbound dimers.
}

compound was claimed to be the most stable $\mathrm{C}_{12} \mathrm{H}_{12}$ isomer despite a considerable strain, ${ }^{47}$ but this was later shown to be incorrect: dimethylnaphthalenes were even more stable. ${ }^{46}$ Apart from the intriguing combination of considerable strain and stability contained in one and the same isomer, a more fundamental issue is at stake also. This is that one should reestablish ${ }^{48}$ the confidence of chemists toward the use of computational methods for the description of energies of hydrocarbons and other larger organic molecules. Moreover, because one may consider unimolecular rearrangement transition structures as isomers of groundstate molecules, ${ }^{47}$ the ability of a computational method to reproduce isomer energy differences has implications also for reaction barriers.

The relative stability at MP2 and $\operatorname{CCSD}(\mathrm{T})$ was, therefore, used as benchmark for comparing different density functionals, and reportedly, ${ }^{47,48}$ many functionals fail to give reliable hydrocarbon isomer energies. However, the reference energies at either MP2 or CCSD(T) show quite considerable variations among each other, which makes it difficult to get a straightforward and reliable set of reference data. This variation was not only observed between respectively the MP2 and $\operatorname{CCSD}(\mathrm{T})$ energies $^{47}$ but also between, e.g., the MP2 energies in different papers. For instance, Schreiner et al. place isomer 31 (not considered here because of the absence of symmetry in it, vide infra) from their paper at $29.1 \mathrm{kcal} \mathrm{mol}^{-1}$ above the $\mathrm{D}_{3 \mathrm{~d}}$-octahedrane (isomer $\mathbf{1}$ in their paper and $2 \mathrm{c}$ in Scheme 2) at the MP2 level, ${ }^{47}$ whereas Perdew, Grimme and coworkers place it at $31.7 \mathrm{kcal} \mathrm{mol}^{-132}$ and Budzelaar et al. at $40.2 \mathrm{kcal} \mathrm{mol}^{-1}$. 46 For comparison, the $\operatorname{CCSD}(\mathrm{T})$ energies are given as either $20.5 \mathrm{kcal} \mathrm{mol}^{-1}$ or $25.0 \mathrm{kcal} \mathrm{mol}{ }^{-1}$.32,47 Therefore, the "reference" energies are found with a variation of about $20 \mathrm{kcal} \mathrm{mol}^{-1}$, which is undesirable when using them to evaluate the performance of density functional methods. Moreover, for the dimethylnaphthalenes, which were shown to be more stable than the octahedrane, ${ }^{46}$ no $\operatorname{CCSD}(\mathrm{T})$ data have been reported yet. Therefore, we have chosen 12 isomers of $\mathrm{C}_{12} \mathrm{H}_{12}$ with quite different bonding patterns and which all contain at least one symmetry element (see Scheme 2, and Supporting Information Table S1 for the isomer names). Seven of these isomers are planar (2a-b, 2d, 2i-l) (note that isomer $2 \mathrm{l}$ has been constrained to be planar by using $\mathrm{C}_{2 \mathrm{v}}$ symmetry, but in reality, a more stable configuration might be obtained by slightly twisting the cyclopentadiene rings out of the plane; however, this does not affect the results obtained here because all calculations were performed on the same planar geometry), one of the nonplanar isomers (2c) has a cage structure, and two of the nonplanar isomers $(\mathbf{2} \mathbf{f}, \mathbf{2 h})$ show (partial) intramolecular $\pi-\pi$ stacking. For each of these isomers, we have optimized the geometry at MP2/cc-pVTZ and subsequently computed the relative energies at the $\operatorname{CCSD}(\mathrm{T}) / \mathrm{CBS}$ level (see below) and at DFT/aug'-cc-pVTZ using the MP2 geometries. Similar to the case for the water-hexamer isomers, ${ }^{10}$ the molecular geometries were similar at either DFT or MP2. ${ }^{47}$

For the CBS extrapolation of the $\operatorname{CCSD}(\mathrm{T})$ energies, we have used two different extrapolation schemes, one for the HartreeFock part and one for the correlation energy. For the Hartree-Fock energy, we used an extrapolation scheme ${ }^{50} E_{H F, X}=E_{a}+E_{b}$. $e^{-E_{c} \cdot X}$ where $E_{\mathrm{a}}, E_{\mathrm{b}}$, and $E_{\mathrm{c}}$ are parameters and $X$ stands for the cardinal number of Dunning's correlation-consistent basis sets ( $X=2$ for cc-pVDZ, $X=3$ for cc-pVTZ, and $X=4$ for ccpVQZ). Using these three basis sets, we have fitted the energies 
<smiles>Cc1cccc2cccc(C)c12</smiles>

2a $\left(\mathrm{C}_{2}\right), 6.13$<smiles>Cc1ccc2ccc(C)cc2c1</smiles>

$2 \mathbf{b}\left(\mathrm{C}_{2 \mathrm{v}}\right), 0.0$

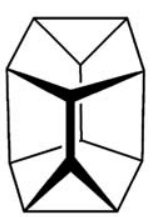

$2 c\left(D_{3 d}\right), 42.85$<smiles>C=c1c(=C)c(=C)c(=C)c(=C)c1=C</smiles><smiles>C1=CC2C(C=C1)C1C=CC=CC21</smiles><smiles>C=C1C=CC2C3C=CC(=C)C3C12</smiles>

2d $\left(\mathrm{D}_{2 \mathrm{~h}}\right), 99.75$ $2 \mathrm{e}\left(\mathrm{C}_{2 \mathrm{~h}}\right), 67.28$ $2 \mathbf{f}\left(\mathrm{C}_{\mathrm{s}}\right), 70.74$<smiles>C1=C[C@H]2C[C@@H]1C1=C2[C@H]2C=C[C@H]1C2</smiles><smiles>C1=C[C@H]2C[C@@H]1C1=C2[C@H]2C=C[C@H]1C2</smiles><smiles>C1=CCC(=C2C=CC=CC2)C=C1</smiles><smiles></smiles><smiles>[13CH3]</smiles>
$2 \mathbf{i}\left(\mathrm{C}_{2 \mathrm{~h}}\right), 56.08$<smiles>C1=C\C=C/C=C\C=C/C=C\C=C/1</smiles>

$2 \mathbf{j}\left(\mathrm{C}_{\mathrm{s}}\right), 121.92$

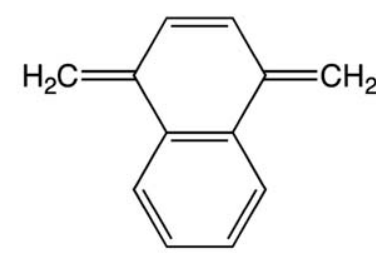

2k $\left(\mathrm{C}_{2 \mathrm{v}}\right), 36.70$<smiles>C=C(C1=CC=CC1)C1=CC=CC1</smiles>

$21\left(\mathrm{C}_{2 \mathrm{v}}\right), 64.84$

Scheme 2. Hydrocarbon $\mathrm{C}_{12} \mathrm{H}_{12}$ isomers (symmetry) with relative $\mathrm{CCSD}(\mathrm{T}) / \mathrm{CBS}$ energies $\left(\mathrm{kcal} \mathrm{mol}^{-1}\right)$.

for each isomer separately to obtain the RHF/CBS energy (see Supporting Information Table S2). The extrapolation of the correlation energy ${ }^{51}$ was then obtained from eq. (3), using the $\operatorname{CCSD}(\mathrm{T})$ energy obtained with the cc-pVTZ $(X=3)$ and cc-pVDZ $(Y=2)$ basis sets (see Supporting Information Table S2).

$$
\begin{aligned}
& E_{\mathrm{CCSD}(\mathrm{T}), \mathrm{CBS}}=E_{\mathrm{HF}, \mathrm{CBS}}+\frac{X^{3} E_{\mathrm{corr}, \mathrm{X}}-Y^{3} E_{\mathrm{corr}, \mathrm{Y}}}{X^{3}-Y^{3}} \\
& E_{\mathrm{corr}, \mathrm{X}}=E_{\mathrm{CCSD}(\mathrm{T}), \mathrm{X}}-E_{\mathrm{HF}, \mathrm{X}}
\end{aligned}
$$

The resulting relative $\operatorname{CCSD}(\mathrm{T}) / \mathrm{CBS}$ energies for the $12 \mathrm{C}_{12} \mathrm{H}_{12}$ isomers are given in Scheme 2, which span a range of $122 \mathrm{kcal}$ $\mathrm{mol}^{-1}$. The most stable isomer is 2,7-dimethylnaphthalene $\mathbf{2 b}$, followed by 1,8-dimethylnaphthalene 2a. Surprisingly, there is another isomer (2k) that is at $\operatorname{CCSD}(\mathrm{T}) / \mathrm{CBS}$ some $6 \mathrm{kcal} \mathrm{mol}^{-1}$ more stable than the octahedrane 2c, which itself is ca. $43 \mathrm{kcal}$ $\mathrm{mol}^{-1}$ higher in energy than $\mathbf{2 b}$. The CCSD(T)/CBS energies for the $\mathbf{2 a}-\mathbf{c}$ isomers obtained here are quite close to the MP2 energies reported recently by Budzelaar and coworkers. ${ }^{46}$ The most unsta- ble $\mathrm{C}_{12} \mathrm{H}_{12}$ isomer studied here is $\mathbf{2} \mathbf{j}$, which results from the steric repulsion coming from three hydrogens that are all inside the ring, and are found at some $1.33 \AA$ from each other. Indeed, the distance to the carbon to which they are attached is significantly smaller $(1.04 \AA)$ than the one for other hydrogens (typically at $1.08 \AA$ ) because of these steric interactions. Finally, the $\mathbf{2 h}$ isomer is more stable than the similar $\mathbf{2 g}$ isomer (87.2 vs. $90.8 \mathrm{kcal}$ $\mathrm{mol}^{-1}$, see Scheme 2) because of favorable intramolecular $\pi-\pi$ stacking interactions that are present in $\mathbf{2 h}$ and absent in $\mathbf{2 g}$.

Both Schleyer and coworkers ${ }^{48}$ and Zhao and Truhlar ${ }^{49}$ proclaimed M05-2X as the most reliable density functional for relative energies of hydrocarbons, which can now be checked also for this set of $12 \mathrm{C}_{12} \mathrm{H}_{12}$ isomers. Given in Table 4 is the error analysis for density functional methods with the aug'-cc-pVTZ basis sets compared to the reference $\operatorname{CCSD}(\mathrm{T}) / \mathrm{CBS}$ energies (see Scheme 2), which were all obtained using the same MP2/ cc-pVTZ geometries. The M05-2X has an MAD value of 6.4 $\mathrm{kcal} \mathrm{mol}^{-1}$, which is considerably higher than might have been expected from the previous studies, where much smaller devia- 
Table 4. Error Analysis for Relative Energies $\left(\mathrm{kcal} \mathrm{mol}^{-1}\right)^{\mathrm{a}}$ of 12 $\mathrm{C}_{12} \mathrm{H}_{12}$ Isomers.

\begin{tabular}{lrrrr}
\hline \multicolumn{1}{c}{ Method } & MD $^{\mathrm{b}}$ & MAD $^{\mathrm{c}}$ & MAX $^{\mathrm{d}}$ & range $^{\mathrm{e}}$ \\
\hline BLYP & 10.12 & 12.05 & 43.41 & 118.31 \\
BLYP-D & 6.64 & 10.03 & 35.89 & 114.92 \\
B3LYP & 9.90 & 10.19 & 30.38 & 120.20 \\
B3LYP-D & 6.86 & 7.65 & 23.80 & 117.50 \\
PBE & 4.71 & 5.30 & 11.81 & 118.77 \\
PBE-D & 2.53 & 3.70 & 8.93 & 116.84 \\
PBEsol & 2.07 & 3.21 & 11.28 & 123.04 \\
PBEsol-D & 1.26 & 2.78 & 11.65 & 122.68 \\
OPBE & 1.25 & 3.69 & 15.27 & 123.89 \\
M05-2X & 6.39 & 6.39 & 11.61 & 132.68 \\
B3PW91 & 5.58 & 5.58 & 12.41 & 126.91 \\
B3PW91-D & 2.10 & 3.15 & 7.97 & 123.84 \\
B2PLYP & 7.76 & 7.76 & 19.52 & 124.22 \\
B2PLYP-D & 6.17 & 6.18 & 16.07 & 122.81 \\
B97-D & 6.31 & 8.38 & 28.16 & 112.60 \\
SSB-D & -0.75 & 3.43 & 19.10 & 122.76 \\
revSSB-D & 0.71 & 4.12 & 17.78 & 125.20 \\
\hline
\end{tabular}

${ }^{a}$ DFT/aug'-cc-pVTZ//MP2/cc-pVTZ compared to reference data $\mathrm{CCSD}(\mathrm{T}) / \mathrm{CBS} / / \mathrm{MP} 2 / \mathrm{cc}-\mathrm{pVTZ}$, for the extrapolation procedure see text.

${ }^{\mathrm{b}}$ Mean deviation compared to the $\operatorname{CCSD}(\mathrm{T}) / \mathrm{CBS}$ data

${ }^{\mathrm{c}}$ Mean absolute deviation compared to the $\operatorname{CCSD}(\mathrm{T}) / \mathrm{CBS}$ data.

${ }^{\mathrm{d}}$ Maximum absolute error compared to the $\operatorname{CCSD}(\mathrm{T}) / \mathrm{CBS}$ data.

${ }^{\mathrm{e}}$ Total range spanned by the 11 different isomers $\left(121.92 \mathrm{kcal} \mathrm{mol}^{-1}\right.$ at $\operatorname{CCSD}(\mathrm{T}) / \mathrm{CBS})$.

tions were reported. And although its MAD value is some 40$50 \%$ smaller than BLYP or B3LYP, it is also more than twice as large as the best density functional (PBEsol-D, MAD value of $2.8 \mathrm{kcal} \mathrm{mol}^{-1}$ ). For these hydrocarbon isomer energies, the effect of the dispersion correction is again beneficial and leads in general to an improvement of some $15-30 \%$ in the MAD value. The only exception is B3PW91-D for which the MAD value drops even further, by $45 \%$ compared to B3PW91. An exceptionally poor performance is observed for B2PLYP and B2PLYP-D, which show MAD values of 7.8 and $6.2 \mathrm{kcal} \mathrm{mol}^{-1}$ respectively (see Table 4).

Good performance is observed for the SSB-D functional, which yields not only a small MAD value of $3.4 \mathrm{kcal} \mathrm{mol}^{-1}$ and a (signed) mean deviation (MD) of $-0.8 \mathrm{kcal} \mathrm{mol}^{-1}$, also the range for all isomers of $122.8 \mathrm{kcal} \mathrm{mol}^{-1}$ is very close to the $\operatorname{CCSD}(\mathrm{T}) / \mathrm{CBS}$ value of $121.9 \mathrm{kcal} \mathrm{mol}^{-1}$. The additional stabilization of $\mathbf{2 h}$ over $\mathbf{2 g}\left(-3.6 \mathrm{kcal} \mathrm{mol}^{-1}\right.$ at $\left.\operatorname{CCSD}(\mathrm{T}) / \mathrm{CBS}\right)$ is excellently reproduced with a value of $-3.8 \mathrm{kcal} \mathrm{mol}^{-1}$ by SSB-D (see Supporting Information Table S3). Moreover, the relative energy of $\mathbf{2} \mathbf{g}$ compared to $\mathbf{2 b}\left(90.8 \mathrm{kcal} \mathrm{mol}^{-1}\right.$ at $\mathrm{CCSD}(\mathrm{T}) / \mathrm{CBS})$ is well reproduced by SSB-D with a value of $89.3 \mathrm{kcal} \mathrm{mol}^{-1}$. Together with OPBE, PBEsol, PBEsol-D, and revSSB-D, these functionals are the only ones that give a good prediction for this relative energy of $\mathbf{2 g}$, namely, less than 3 kcal $\mathrm{mol}^{-1}$ (see Supporting Information Table S3), with the other functionals giving an error between 7 and $28 \mathrm{kcal} \mathrm{mol}^{-1}$. The maximum error for SSB-D is observed for the octahedrane 2c, which it predicts at too low energy. This isomer is, however, a difficult molecule for all density functional methods, which give errors for its relative energy up to $43 \mathrm{kcal} \mathrm{mol}^{-1}$. The only other problematic molecule for SSB-D is isomer 2d, which it predicts at too high energy. For all other isomers, SSB-D predicts the relative energy with a deviation between 0.2 and $2.6 \mathrm{kcal} \mathrm{mol}^{-1}$.

\section{Grimme's Difficult Systems}

Grimme and coworkers proposed two difficult systems for density functional methods, i.e., the branching energy of linear versus branched octane and the dimerization of anthracene. The spin-component scaled MP2 gave good results, but none of the density functional methods they tested gave even the correct sign, let alone coming close to the actual reference value. The use of the dispersion correction was shown to be helpful but only in a very limited sense and did not result in good results either. Last year, we reported ${ }^{19}$ that our SSB-D functional performs excellently for these difficult systems with predicted energies that are within $0.5 \mathrm{kcal} \mathrm{mol}^{-1}$ of the reference data. Not all of the density functionals we have used in this article have been tested for these challenging systems, which is why we return to them here.

Similar to what we observed with an STO basis set, our SSB-D/aug'-cc-pVTZ results are excellent (see Table 5) with values of $+1.5 \mathrm{kcal} \mathrm{mol}^{-1}$ for the branching energy and +9.6 $\mathrm{kcal} \mathrm{mol}{ }^{-1}$ for the dissociation of the anthracene dimer. The best estimates for the reference data are, respectively, $+1.9 \pm$ $0.5 \mathrm{kcal} \mathrm{mol}^{-1}$ and $+9 \pm 3 \mathrm{kcal} \mathrm{mol}^{-1}$ (see Table 5). ${ }^{17,18}$ The branching energy is also well predicted by PBE-D, B2PLYP-D and B97-D with values of, respectively, $+2.3,+2.3$, and +2.1 $\mathrm{kcal} \mathrm{mol}^{-1}$. The other density functional methods are less successful with values that either too low or too high. For example, M05-2X gives a branching energy of $+0.4 \mathrm{kcal} \mathrm{mol}^{-1}$, i.e., 1.5

Table 5. Relative Energies $\left(\mathrm{kcal} \mathrm{mol}^{-1}\right)^{\mathrm{a}}$ for Grimme's Difficult Systems (see Scheme 3).

\begin{tabular}{lcrcc}
\hline \multicolumn{1}{c}{ Method } & 3a & \multicolumn{1}{c}{ 3b } & Anthr.-dimer $\mathbf{4 b}$ & 2.Anthr.-monomer 4a \\
\hline best estimate $^{\mathrm{b}}$ & 0 & $1.9 \pm 0.5$ & 0 & $9 \pm 3$ \\
BLYP & 0 & -9.08 & 0 & -34.12 \\
BLYP-D & 0 & 3.22 & 0 & -9.12 \\
B3LYP & 0 & -8.05 & 0 & -23.64 \\
B3LYP-D & 0 & 2.71 & 0 & -1.76 \\
PBE & 0 & -5.44 & 0 & -13.15 \\
PBE-D & 0 & 2.25 & 0 & 2.48 \\
PBEsol & 0 & -2.00 & 0 & 0.41 \\
PBEsol-D & 0 & -0.51 & 0 & 9.87 \\
OPBE & 0 & -14.23 & 0 & -21.38 \\
M05-2X & 0 & 0.42 & 0 & 5.47 \\
B3PW91 & 0 & -5.08 & 0 & -5.86 \\
B3PW91-D & 0 & 7.22 & 0 & 19.15 \\
B2PLYP & 0 & -3.33 & 0 & -6.89 \\
B2PLYP-D & 0 & 2.31 & 0 & 4.56 \\
B97-D & 0 & 2.09 & 0 & -7.03 \\
SSB-D & 0 & 1.47 & 0 & 9.59 \\
revSSB-D & 0 & -3.90 & 0 & 7.57 \\
\hline
\end{tabular}

a'Obtained with aug'-cc-pVTZ basis on SSB-D/TZ2P geometries.

${ }^{\mathrm{b}}$ From ref. 18 (branching energy) and ref. 17 (anthracene dimerization). 


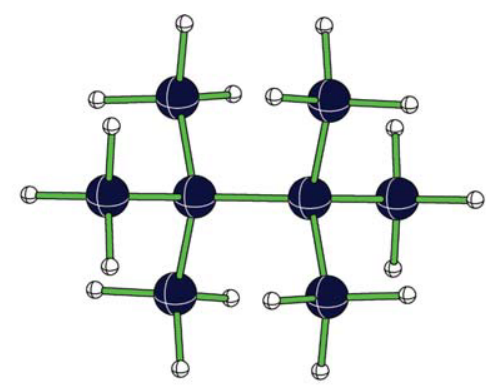

3a

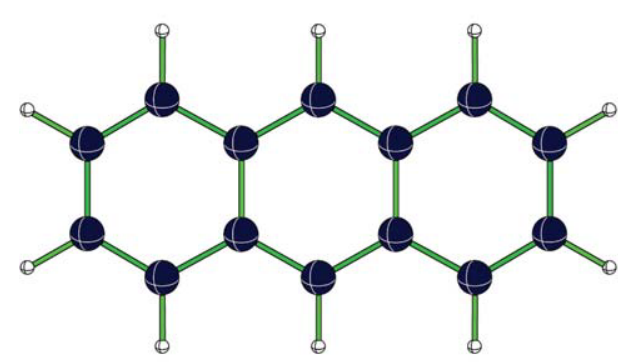

$2 \cdot 4 a$

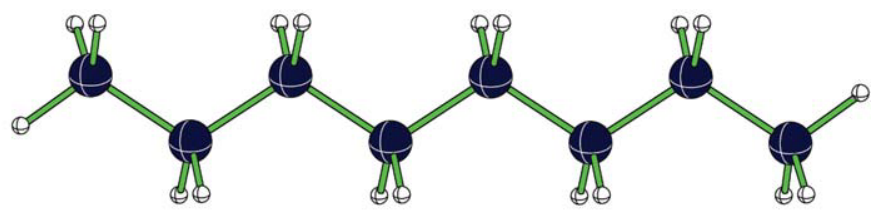

3b

Scheme 3. Grimme's difficult systems: branching energy of octane (top) ${ }^{18}$ and dimerization of anthracene (bottom) ${ }^{17}$.

kcal $\mathrm{mol}^{-1}$ too low, whereas B3LYP-D, BLYP-D, and B3PW91-D give a too high branching energy with values between +2.7 and $+7.2 \mathrm{kcal} \mathrm{mol}^{-1}$. It can be seen that the dispersion correction is needed for this interaction, as in all cases it brings the branching energy value closer to the reference value. As already shown by Grimme and coworkers, none of the functionals without the dispersion correction works well, i.e., they give branching energies between -2.0 and $-14.2 \mathrm{kcal} \mathrm{mol}^{-1}$. The only exception is M05-2X, but this functional was explicitly parameterized (using 22 fit parameters) for a number of interactions, including $\pi-\pi$ stacking, even though for this system it does not give as good a result as other functionals. Surprisingly, the PBEsol-D functional fails for this system of intramolecular dispersion, as it gives a branching energy of $-0.5 \mathrm{kcal} \mathrm{mol}^{-1}$ and is thus the only dispersion-corrected functional that incorrectly favors linear octane over branched octane. In this case, SSB-D performs much better than revSSB-D.

For the dissociation energy of the anthracene dimer, which should be positive by ca. $9 \mathrm{kcal} \mathrm{mol}^{-1}$ and thus in favor of dimerization, the dispersion correction again helps to bring the value closer to the best estimate reference data. However, there are very few density functionals that are able to give an accurate prediction for this dissociation energy, which are SSB-D (+9.6 kcal mol $\left.{ }^{-1}\right)$, PBEsol-D (+9.9 $\left.\mathrm{kcal} \mathrm{mol}^{-1}\right)$, and perhaps revSSB-D (+7.6 kcal $\left.\mathrm{mol}^{-1}\right)$. The first two are in excellent agreement with the estimated QCISD(T)/cc-pVQZ and fixed-node Diffusion-Monte-Carlo results
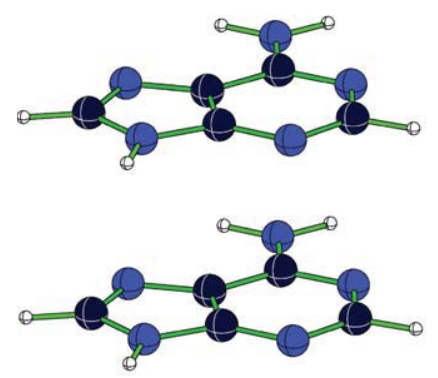

P1
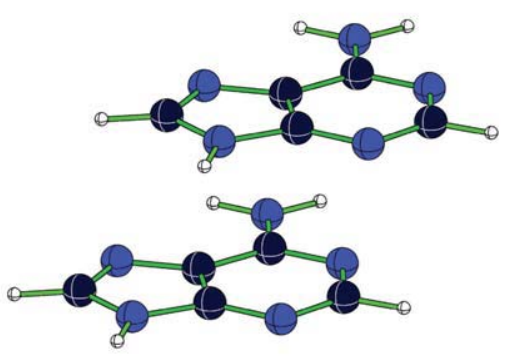

P2

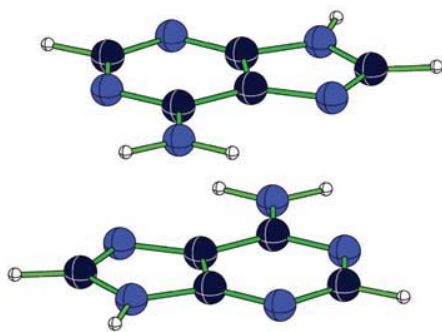

P4

Scheme 4. Three orientations of $\pi-\pi$ stacked adenine dimer ${ }^{53}$ : parallel (P1), parallel-displaced (P2) and antiparallel (P4). 
Table 6. Error Analysis ${ }^{\mathrm{a}}$ for $\pi-\pi$ Stacking Energies of Adenine Dimer $\left(\mathrm{kcal} \mathrm{mol}^{-1}\right.$ ) Compared to $\mathrm{CBS}(\mathrm{T})^{\mathrm{b}}$.

\begin{tabular}{lrrrr}
\hline Method & $\begin{array}{c}\text { orientation } \\
\mathrm{P}^{\mathrm{c}, \mathrm{d}}\end{array}$ & $\begin{array}{r}\text { orientation } \\
\mathrm{P}^{\mathrm{c}, \mathrm{d}}\end{array}$ & $\begin{array}{r}\text { orientation } \\
\mathrm{P}^{\mathrm{c}, \mathrm{d}}\end{array}$ & $\begin{array}{r}\text { average } \\
\mathrm{MAD}^{\mathrm{e}}\end{array}$ \\
\hline TPSS-D $^{\mathrm{f}}$ & 0.74 & 0.77 & 0.99 & 0.83 \\
BLYP & 13.14 & 11.79 & 13.35 & 12.76 \\
BLYP-D & 0.52 & 0.73 & 0.99 & 0.75 \\
B3LYP & 11.58 & 10.28 & 11.59 & 11.15 \\
B3LYP-D & 0.53 & 0.60 & 0.77 & 0.64 \\
PBE & 8.77 & 8.00 & 9.12 & 8.63 \\
PBE-D & 0.83 & 1.09 & 1.39 & 1.10 \\
PBEsol & 6.66 & 6.27 & 7.07 & 6.67 \\
PBEsol-D & 0.84 & 0.96 & 1.19 & 1.00 \\
OPBE & 19.23 & 17.10 & 19.41 & 18.58 \\
M05-2X & 3.92 & 3.68 & 3.23 & 3.61 \\
B3PW91 & 9.10 & 8.35 & 9.29 & 8.91 \\
B3PW91-D & 3.55 & 2.71 & 3.07 & 3.11 \\
B2PLYP & 5.57 & 4.94 & 5.60 & 5.37 \\
B2PLYP-D & 0.45 & 0.34 & 0.38 & 0.39 \\
B97-D & 0.30 & 0.57 & 0.83 & 0.57 \\
SSB-D & 0.32 & 0.24 & 0.53 & 0.36 \\
revSSB-D & 1.21 & 0.78 & 1.54 & 1.18 \\
\hline
\end{tabular}

${ }^{a}$ DFT(-D)/aug'-cc-pVTZ results, corrected for BSSE

${ }^{b}$ From ref. 53, obtained at $\mathrm{CBS}(\mathrm{T})(\mathrm{MP} 2 / \mathrm{CBS}$ corrected by $\operatorname{CCSD}(\mathrm{T})$ with small basis set).

${ }^{\mathrm{c}}$ For orientations see Scheme 4.

${ }^{\mathrm{d}}$ Mean absolute deviation w.r.t. CBS(T) energies from ref. 53.

${ }^{\mathrm{e}}$ Average of MAD values for orientations $\mathrm{P} 1, \mathrm{P} 2$, and $\mathrm{P} 4$.

${ }^{\mathrm{f}}$ From ref. 53, obtained with $6-311++\mathrm{G}(3 \mathrm{df}, 3 \mathrm{pd})$ basis set.

of +9.5 and $9 \pm 2 \mathrm{kcal} \mathrm{mol}^{-1}$, respectively, whereas the revSSB-D value is probably already too low. All other density functionals give dissociation values that are substantially lower (between -34.1 and $+5.5 \mathrm{kcal} \mathrm{mol}^{-1}$ ), and the majority even gives the wrong sign (see Table 5). It is again striking that the much heralded $^{43}$ B2PLYP and its dispersion-corrected B2PLYP-D give disappointing results for the dissociation of the anthracene dimer, which was already reported before in ref. 49. The problem is already present for B2PLYP that similar to other functionals without dispersion correction is unable to give the correct sign for this dissociation energy.

\section{Stacking Energies of Adenine Dimers}

Sponer and coworkers reported very recently a detailed study ${ }^{53}$ on the binding energy of $\pi-\pi$ stacked adenine dimers, in which they investigated nine parallel dimers and three nonparallel ones. We have selected three characteristic orientations (see Scheme 4), and again investigated them with all density functionals used so far in this article. As the reference CBS(T) energies (MP2/CBS corrected by $\triangle \mathrm{CCSD}(\mathrm{T})$ obtained with a small basis set) were corrected for BSSE, we do the same here. Given in Table 6 is the error analysis for the list of functionals (full data are available in the Supporting Information in Supporting Information Table S4), which now also includes the TPSS-D data from the original paper. ${ }^{53}$ Similar to the other systems we have studied so far, the dispersion correction plays a major role for a good description of these stacking interactions. For the functionals without it, errors of 6.7 to
$18.6 \mathrm{kcal} \mathrm{mol}^{-1}$ are observed (see Table 6) and these functionals, therefore, completely fail for stacking interactions, as already noted before. ${ }^{5}$ The only exception is M05-2X that gives an energy MAD of $3.6 \mathrm{kcal} \mathrm{mol}^{-1}$, but this functional was parameterized against stacking energies so in principle does not need the dispersion correction. However, the inclusion of Grimme's dispersion correction does not correct these errors completely, as can be seen for e.g. PBE-D (MAD value of $1.1 \mathrm{kcal} \mathrm{mol}^{-1}$ ) or B3PW91-D (MAD value of $\left.3.1 \mathrm{kcal} \mathrm{mol}^{-1}\right)$. Reasonable to good performance is observed for some dispersion corrected functionals (B3LYP-D, BLYP-D, B97-D) with errors between 0.6 and $0.8 \mathrm{kcal} \mathrm{mol}^{-1}$. Excellent results are obtained only with B2PLYP-D (MAD value of $0.39 \mathrm{kcal} \mathrm{mol}^{-1}$ ) and SSB-D (MAD of only $0.36 \mathrm{kcal} \mathrm{mol}^{-1}$ ).

\section{Concluding Remarks}

Our recently developed SSB-D functional yields highly satisfactory results for weakly bound systems, including the notoriously difficult systems that lead to dramatic failure in the case of other functionals. SSB-D, thus, outperforms the other functionals, including the new revSSB-D functional presented herein, and is confirmed as a solid all-round density functional (see also refs. $19,27,28,31)$.

This follows from our investigations on the performance of several density functional methods for intra- and intermolecular dispersion interactions. For most functionals, we have studied the performance both with and without Grimme's empirical dispersion correction. The functionals were applied to a wide variety of systems, which consist of water-hexamer isomers, noble-gas dimers, hydrocarbon $\mathrm{C}_{12} \mathrm{H}_{12}$ isomers, the branching energy of linear versus branched octane, dissociation of the covalently bound anthracene dimer, and stacking within the adenine dimer. For all of these systems, it was shown that adding the dispersion correction is beneficial. However, because of the intrinsic differences in the original uncorrected functionals, there remain sizeable differences between the results from the different density functionals. Likewise, the deviation from reference data obtained at $\operatorname{CCSD}(\mathrm{T}) / \mathrm{CBS}$ or with experiments, also varies considerably. Without dispersion corrections, the deviations from the reference data is very large, i.e. up to $4.7 \mathrm{kcal}$ $\mathrm{mol}^{-1}$ for the water-hexamers (obtained with OPBE), to $12.1 \mathrm{kcal}$ $\mathrm{mol}^{-1}$ for the $12 \mathrm{C}_{12} \mathrm{H}_{12}$ isomers (with BLYP), to $43 \mathrm{kcal} \mathrm{mol}^{-1}$ for the anthracene dimer (with BLYP) and up to $18.6 \mathrm{kcal} \mathrm{mol}^{-1}$ for the stacked adenine dimer (with OPBE). With dispersion corrections, the deviation can still be large as is the case for e.g. BLYP-D for the twelve $\mathrm{C}_{12} \mathrm{H}_{12}$ isomers (deviation $10.0 \mathrm{kcal} \mathrm{mol}^{-1}$ ) and anthracene dimer (deviation $18.1 \mathrm{kcal} \mathrm{mol}^{-1}$ ), or B3PW91-D for the branching of octane (deviation $5.3 \mathrm{kcal} \mathrm{mol}^{-1}$ ), dimerization of anthracene (deviation $10.2 \mathrm{kcal} \mathrm{mol}^{-1}$ ) and stacked adenine (deviation $3.1 \mathrm{kcal} \mathrm{mol}^{-1}$ ). At the same time, B3PW91-D does work well for the $12 \mathrm{C}_{12} \mathrm{H}_{12}$ isomers (deviation $3.2 \mathrm{kcal} \mathrm{mol}^{-1}$ ). The same pattern of working well for some systems but combined with dramatic failure for others is also observed for other functionals like PBEsol-D and surprisingly also the B2PLYP-D functional. This latter functional is often heralded as the "best" density functional but is found to give large errors for the $12 \mathrm{C}_{12} \mathrm{H}_{12}$ isomers and the dimerization of anthracene. Almost all density functionals give substantial to large deviations from the reference data for at least two systems, 
with the exception of our recently presented SSB-D functional that works well for all systems studied here.

The SSB-D functional yields deviations from the reference data of $0.6 \mathrm{kcal} \mathrm{mol}^{-1}$ for the water hexamers (with the correct ordering of the isomers), $0.2 \AA$ and $0.3 \mathrm{kcal} \mathrm{mol}^{-1}$ for the noble-gas dimers, $3.4 \mathrm{kcal} \mathrm{mol}^{-1}$ for the twelve $\mathrm{C}_{12} \mathrm{H}_{12}$ isomers, $0.4 \mathrm{kcal} \mathrm{mol}^{-1}$ for the branching energy of octane, $0.6 \mathrm{kcal}$ $\mathrm{mol}^{-1}$ for the dimerization of anthracene, and $0.4 \mathrm{kcal} \mathrm{mol}^{-1}$ for the stacked adenine dimer. Apart from the water hexamers (where revSSB-D gives an even smaller deviation of $0.2 \mathrm{kcal}$ $\mathrm{mol}^{-1}$ ), it performs significantly better than the revSSB-D functional presented here, and we, therefore, recommend the use of the original SSB-D functional.

\section{Acknowledgments}

Excellent service by the Stichting Academisch Rekencentrum Amsterdam (SARA) and the Centre de Supercomputació de Catalunya (CESCA) is gratefully acknowledged. The following organizations are thanked for financial support: the Ministerio de Ciencia e Innovación (MICINN, project numbers CTQ200803077/BQU and CTQ2008-06532/BQU), and the DIUE of the Generalitat de Catalunya (project numbers 2009SGR637 and 2009SGR528). Support for the research of M. Solà was received through the ICREA Academia 2009 prize for excellence in research funded by the DIUE of the Generalitat de Catalunya. The Cartesian coordinates of all orientations of the anthracene dimers were kindly provided by Sponer and coworkers.

\section{References}

1. van der Wijst, T.; Fonseca Guerra, C.; Swart, M.; Bickelhaupt, F. M. Chem Phys Lett 2006, 426, 415.

2. Fonseca Guerra, C.; Bickelhaupt, F. M.; Snijders, J. G.; Baerends, E. J. Chem Eur J 1999, 5, 3581.

3. Fonseca Guerra, C.; Bickelhaupt, F. M.; Snijders, J. G.; Baerends, E. J. J Am Chem Soc 2000, 122, 4117.

4. Fonseca Guerra, C.; Bickelhaupt, F. M. Angew Chem Int Ed 2002, 41, 2092.

5. Swart, M.; van der Wijst, T.; Fonseca Guerra, C.; Bickelhaupt, F. M. J Mol Model 2007, 13, 1245.

6. Swart, M.; Fonseca Guerra, C.; Bickelhaupt, F. M. J Am Chem Soc 2004, 126, 16718.

7. Helgaker, T.; Ruden, T. A.; Jorgensen, P.; Olsen, J.; Klopper, W. J Phys Org Chem 2004, 17, 913.

8. Bak, K. L.; Gauss, J.; Jørgensen, P.; Olsen, J.; Helgaker, T.; Stanton, J. F. J Chem Phys 2001, 114, 6548.

9. Coriani, S.; Haaland, A.; Helgaker, T.; Jørgensen, P. ChemPhysChem 2006, 7, 245.

10. Dahlke, E. E.; Olson, R. M.; Leverentz, H. R.; Truhlar, D. G. J Phys Chem A 2008, 112, 3976.

11. Bates, D. M.; Tschumper, G. S. J Phys Chem A 2009, 113, 3555.

12. Zhang, Y. K.; Pan, W.; Yang, W. J Chem Phys 1997, 107, 7921.

13. Swart, M.; Solà, M.; Bickelhaupt, F. M. J Comput Meth Sci Eng 2009, 9, 69.

14. Wesolowski, T. A.; Parisel, O.; Ellinger, Y.; Weber, J. J Phys Chem A 1997, 101, 7818.

15. Perdew, J. P.; Burke, K.; Ernzerhof, M. Phys Rev Lett 1996, 77, 3865; Erratum: Phys Rev Lett 1997, 78, 1396.
16. Swart, M.; Solà, M.; Bickelhaupt, F. M. In Handbook of Computational Chemistry Research; Collett, C. T.; Robson, C. D., Eds.; Nova Science: Hauppauge, USA, 2010, pp 97-125.

17. Grimme, S.; Diedrich, C.; Korth, M. Angew Chem Int Ed 2006, 45, 625.

18. Grimme, S. Angew Chem Int Ed 2006, 45, 4460.

19. Swart, M.; Solà, M.; Bickelhaupt, F. M. J Chem Phys 2009, 131, 094103.

20. Handy, N. C.; Cohen, A. J. Mol Phys 2001, 99, 403.

21. Swart, M.; Ehlers, A. W.; Lammertsma, K. Mol Phys 2004, 102, 2467.

22. Swart, M. J Chem Theory Comp 2008, 4, 2057.

23. Jurecka, P.; Sponer, J.; Cerny, J.; Hobza, P. Phys Chem Chem Phys 2006, 8, 1985.

24. Grimme, S. J Comput Chem 2004, 25, 1463.

25. Grimme, S. J Comput Chem 2006, 27, 1787.

26. Grimme, S.; Antony, J.; Ehrlich, S.; Krieg, H. J Chem Phys 2010, 132, 154104.

27. Swart, M.; Solà, M.; Bickelhaupt, F. M. J Chem Theory Comput (in press); DOI: 10.1021/ct100454c.

28. Johansson, M. P.; Swart, M. J Chem Theory Comput (submitted).

29. Swart, M.; van Duijnen, P. Th. Int J Quantum Chem (in press); DOI: 10.1002/qua.22855.

30. Johansson, M. P.; Swart, M. Inorg Chem (submitted).

31. Armangué, L.; Solà, M.; Swart, M. J Phys Chem A (submitted).

32. Csonka, G. I.; Ruzsinszky, A.; Perdew, J. P.; Grimme, S. J Chem Theory Comput 2008, 4, 888.

33. Tkatchenko, A.; Scheffler, M. Phys Rev Lett 2009, 102, 073005.

34. Bylaska, E. J.; de Jong, W. A.; Kowalski, K.; Straatsma, T. P.; Valiev, M.; Wang, D.; Apra, E.; Windus, T. L.; Hirata, S.; Hackler, M. T.; Zhao, Y.; Fan, P.-D.; Harrison, R. J.; Dupuis, M.; Smith, D. M. A.; Nieplocha, J.; Tipparaju, V.; Krishnan, M.; Auer, A. A.; Nooijen, M.; Brown, E.; Cisneros, G.; Fann, G. I.; Fruchtl, H.; Garza, J.; Hirao, K.; Kendall, R.; Nichols, J. A.; Tsemekhman, K.; Wolinski, K.; Anchell, J.; Bernholdt, D.; Borowski, P.; Clark, T.; Clerc, D.; Dachsel, H.; Deegan, M.; Dyall, K.; Elwood, D.; Glendening, E.; Gutowski, M.; Hess, A.; Jaffe, J.; Johnson, B.; Ju, J.; Kobayashi, R.; Kutteh, R.; Lin, Z.; Littlefield, R.; Long, X.; Meng, B.; Nakajima, T.; Niu, S.; Pollack, L.; Rosing, M.; Sandrone, G.; Stave, M.; Taylor, H.; Thomas, G.; van Lenthe, J.; Wong, A.; Zhang Z. NWChem 5.1.1, A Computational Chemistry Package for Parallel Computers; Pacific Northwest National Laboratory: Richland, Washington, 2006.

35. Frisch, M. J.; Trucks, G. W.; Schlegel, H. B.; Scuseria, G. E.; Robb, M. A.; Cheeseman, J. R.; Scalmani, G.; Barone, V.; Mennucci, B.; Petersson, G. A.; Nakatsuji, H.; Caricato, M.; Li, X.; Hratchian, H. P.; Izmaylov, A. F.; Bloino, J.; Zheng, G.; Sonnenberg, J. L.; Hada, M.; Ehara, M.; Toyota, K.; Fukuda, R.; Hasegawa, J.; Ishida, M.; Nakajima, T.; Honda, Y.; Kitao, O.; Nakai, H.; Vreven, T.; Montgomery, J. A., Jr.; Peralta, J. E.; Ogliaro, F.; Bearpark, M.; Heyd, J. J.; Brothers, E.; Kudin, K. N.; Staroverov, V. N.; Kobayashi, R.; Normand, J.; Raghavachari, K.; Rendell, A.; Burant, J. C.; Iyengar, S. S.; Tomasi, J.; Cossi, M.; Rega, N.; Millam, J. M.; Klene, M.; Knox, J. E.; Cross, J. B.; Bakken, V.; Adamo, C.; Jaramillo, J.; Gomperts, R.; Stratmann, R. E.; Yazyev, O.; Austin, A. J.; Cammi, R.; Pomelli, C.; Ochterski, J. W.; Martin, R. L.; Morokuma, K.; Zakrzewski, V. G.; Voth, G. A.; Salvador, P.; Dannenberg, J. J.; Dapprich, S.; Daniels, A. D.; Farkas, O.; Foresman, J. B.; Ortiz, J. V.; Cioslowski, J.; Fox, D. J. Gaussian 09, revision A.02; Gaussian Inc., Wallingford CT, 2009.

36. Swart, M.; Bickelhaupt, F. M. J Comput Chem 2008, 29, 724.

37. Swart, M.; Bickelhaupt, F. M. Int J Quant Chem 2006, 106, 2536.

38. Stanton, J. F.; Gauss, J.; Harding, M. E.; Szalay, P. G. CFOUR 1.2; Austin, Texas, USA, 2010. 
39. Harding, M. E.; Metzroth, T.; Gauss, J. J Chem Theory Comput 2008, 4, 64.

40. van Mourik, T.; Dunning, T. H., Jr. J Chem Phys 1999, 111, 9248.

41. Gdanitz, R. J. Chem Phys Lett 2001, 348, 67.

42. Slavicek, P.; Kalus, R.; Paska, P.; Odvarkova, I.; Hobza, P.; Malijevsky, A. J Chem Phys 2003, 119, 2102.

43. Schwabe, T.; Grimme, S. Acc Chem Res 2008, 41, 569.

44. Lee, C.-H.; Liang, S.; Haumann, T.; Boese, R.; de Meijere, A. Angew Chem Int Ed 1993, 32, 559.

45. de Meijere, A.; Lee, C.-H.; Kuznetsov, M. A.; Gusev, D. V.; Kozhushkov, S. I.; Fokin, A. A.; Schreiner, P. R. Chem Eur J 2005, 11, 6175 .

46. Shamov, G. A.; Budzelaar, P. H. M.; Schreckenbach, G. J Chem Theory Comput 2010, 6, 477.
47. Schreiner, P. R.; Fokin, A. A.; Pascal, R. A., Jr.; de Meijere, A. Org Lett 2006, 8, 3635.

48. Wodrich, M. D.; Corminboeuf, C.; Schreiner, P. R.; Fokin, A. A.; Schleyer, P. v. R. Org Lett 2007, 9, 1851.

49. Zhao, Y.; Truhlar, D. G. Org Lett 2006, 8, 5753.

50. Halkier, A.; Helgaker, T.; Jørgensen, P.; Klopper, W.; Olsen, J. Chem Phys Lett 1999, 302, 437.

51. Halkier, A.; Helgaker, T.; Jørgensen, P.; Klopper, W.; Koch, H.; Olsen, J.; Wilson, A. K. Chem Phys Lett 1998, 286, 243.

52. Sancho-García, J. C.; Pérez-Jiménez, A. J. J Chem Phys 2009, 131, 084108.

53. Morgado, C. A.; Jurecka, P.; Svozil, D.; Hobza, P.; Sponer, J. Phys Chem Chem Phys 2010, 12, 3522. 